\title{
Seasonal steroid hormone levels and their relation to reproduction in the Western Diamond-backed Rattlesnake, Crotalus atrox (Serpentes: Viperidae)
}

\author{
Emily N. Taylor, Dale F. DeNardo, and David H. Jennings
}

\begin{abstract}
We report seasonal variation in steroid hormone levels in blood samples from free ranging Western Diamond backed Rattle snakes (Crotalus atrox), and the relationship between these hormones and events in the reproductive cycle. At a field site in the Sonoran Desert of south central Arizona, we collected monthly blood samples over the course of two active seasons from 17 ra diotelemetered females, and over three active seasons from 103 randomly encountered males. We used radioimmunoassay to measure plasma levels of $17 \beta$ estradiol, progesterone, corticosterone, and testosterone in samples from females, and corticosterone and testosterone in samples from males. Non reproductive females have consistently low levels of circulating $17 \beta$ estradiol, pro gesterone, and testosterone throughout the year. In reproductive females, $17 \beta$ estradiol levels increase dramatically and testosterone levels increase modestly during vitellogenesis in April and May, while progesterone levels increase dramatically at ovulation in June and then steadily decline until parturition in August. Corticosterone levels appear relatively constant in non reproductive females, whereas reproductive females show increased levels at the end of gestation. Plasma testosterone levels in males are low in early summer and are elevated during spring and late summer, corresponding to the two mating periods of $C$. atrox. Plasma cortico sterone levels in males did not vary seasonally and were not related to testosterone levels.
\end{abstract}

Keywords: Crotalus; Rattlesnake; Reproduction; Estradiol; Corticosterone; Progesterone; Testosterone

\section{Introduction}

Steroid hormones regulate many physiological processes in vertebrates, including reproduction, growth, and homeostatic mechanisms such as water and energy balance. The roles of steroid hormones in reproduction have been well-studied in many vertebrate taxa, and sex steroids in particular are integral regulators of reproductive behaviors and functions across vertebrates. In many species, estrogens (e.g., 17 $\beta$-estradiol, E2) stimulate sexual behavior and vitellogenesis in females, while androgens (e.g., testosterone, T) stimulate sexual behavior and spermatogenesis in males (Norris, 1997). Progestins (e.g., progesterone, P), secreted primarily from the corpus luteum and placenta, function to maintain pregnancy in viviparous taxa (Custodia-Lora and Callard, 2002). The adrenal glucocorticoids (e.g., corticosterone, B) are elevated during reproduction in some species, acting to mobilize energy for costly reproductive behaviors (Moore and Jessop, 2003).

Studies of the interactions among steroids, behavior, and reproduction have been instrumental in elucidating many aspects of reproductive physiology, from understanding basic mechanisms to designing treatments for reproductive dysfunction to broadening our knowledge about the diversity of organism environment interactions. Although the structures and many of the functions of steroid hormones are conserved among vertebrates (Norris, 1997), interspecific differences in steroidal regulation of reproduction may reflect adaptations to different ecological pressures (Wingfield et al., 1997). Knowledge of the mechanisms by which steroids regulate reproduction aids in elucidating the ways that 
taxa cope with diverse environmental pressures and broadens our understanding of organism environment interactions. While experiments that manipulate circulating hormone levels are key to understanding the mechanisms of hormone action, there is similar value in conducting descriptive studies of diverse taxa because they provide information about how endogenous hormones regulate a myriad of reproductive strategies.

Relatively few studies have examined the relationship between hormones and reproduction in snakes (reviewed in Moore and Lindzey, 1992). Descriptive studies conducted on natural populations of snakes will provide information essential to gaining a better understanding of the diversity of mating systems and their physiological regulation (Gans and Crews, 1992; Schuett, 1997). In this study, we describe how seasonal variations in plasma levels of several steroid hormones are related to events in the reproductive cycle of free-ranging Western Diamond-backed Rattlesnakes (Crotalus atrox). We measured plasma levels of E2, P, B, and T in samples from reproductive and non-reproductive females, and $\mathrm{B}$ and $\mathrm{T}$ in samples from males. C. atrox is a good study organism for examining hormonal regulation of reproduction for several reasons. First, they are abundant and spend much of their time above ground, allowing for sequential assessment of large numbers of individuals in the natural environment. Second, female rattlesnakes tend to exhibit less-than-annual reproduction (Klauber, 1972), allowing simultaneous comparison of steroid levels in reproductive and non-reproductive individuals occupying the same habitat. Finally, C. atrox has two mating seasons per year but only reproduces once (Aldridge and Duvall, 2002), permitting independent examination of hormonal mechanisms regulating mating behavior from those regulating other physiological processes such as gametogenesis or vitellogenesis.

\section{Methods}

\subsection{Study site}

The study site is a $1.5 \times 1.0 \mathrm{~km}$ area of upland Sonoran Desert (elevation $800900 \mathrm{~m}$ ) located approximately $33 \mathrm{~km}$ NNE of Tucson, Arizona. The habitat consists of rocky volcanic hillsides and sandy plains with intermittent washes. The vegetation is dominated by creosote, palo verde, and many cactus species.

\subsection{Field monitoring and blood collection}

Seventeen female $C$. atrox were implanted with 11 -g radiotransmitters (\#SI-2T, Holohil, Carp, Ont., Canada) and individually marked for identification with 12mm PIT tags (AVID, Norco, California, USA) and a unique three-color code of acrylic paint injected into the rattle string. Snakes were located several times per week and bled at monthly intervals. Once located, snakes were coaxed into a plastic tube and bled from the caudal vein within five minutes of capture. This time interval is short enough that plasma levels of B are unaffected by capture stress (G. Schuett and E. Taylor, unpublished data). One milliliter samples of blood were collected into $1.5 \mathrm{~mL}$ plastic tubes and centrifuged in the lab within $24 \mathrm{~h}$ of collection. Within this time period, steroid concentrations in blood samples do not become altered (Taylor and Schuett, 2004). Plasma was collected and stored at $-80^{\circ} \mathrm{C}$ until radioimmunoassay. We were unable to obtain blood samples from each snake at every month of the study because snakes were occasionally inaccessible (i.e., underground), and snakes were sampled for varying periods of time because of differences in date of capture, death, and variable radiotelemeter life. Also, snakes overwintered underground from October/ November through February, so we only obtained samples from snakes during the active season. The mean number of monthly blood samples collected from the 17 female snakes in this study was $8.3 \pm 3.7$ samples, for a total of 181 blood samples collected and analyzed during two active seasons (4/00 to 9/01).

Since we wanted to relate steroid hormone levels to events in the reproductive cycle, we monitored the reproductive condition of snakes at monthly intervals during the reproductive season using portable ultrasonography (Concept/MCV, Dynamic Imaging, Livingston, Scotland). We designated snakes as vitellogenic (presence of yolked follicles clustered in a restricted area), ovulated (presence of large yolked ova arranged linearly throughout the caudal third of the snake), pregnant (presence of fetuses), or non-reproductive (absence of detectable follicles or the presence of small, pre-vitellogenic follicles). Stage of pregnancy was estimated by fetus size and proportion of yolk remaining. To more closely evaluate peri-parturient hormone levels and to collect reproductive output data, snakes were captured and brought into the lab one to several weeks prior to parturition. While in the laboratory, we took blood samples weekly, and two days after parturition. Snakes were released at the sites of capture along with their neonates one week after parturition.

Male C. atrox were not implanted with radiotransmitters; instead, we obtained blood samples from males that we randomly encountered while radiotracking the females. Males were marked and sampled in the same manner as females. We obtained and analyzed 170 blood samples from 103 males during three active seasons $(4 / 00$ to $10 / 02)$.

\subsection{Radioimmunoassay}

Plasma steroid levels in samples from female C. atrox were determined following the methods of Moore et al. 
(1991). Briefly, samples, including those containing unlabeled steroid (Sigma Chemical, St. Louis, MO) for internal standards, were allowed to equilibrate overnight with $2000 \mathrm{cpm}$ of each radioactive hormone (P: ICN, Costa Mesa, CA; T, E2, B: New England Nuclear, Boston, MA) for determination of individual recoveries. Each sample was extracted twice with $2.0 \mathrm{~mL}$ of ethyl ether. Ether phases were pooled, dried under nitrogen, and resuspended in iso-octane containing ethylene glycol. To separate hormones from each other, and from neutral lipids that may interfere with the radioimmunoassay, all samples were subjected to column chromatography using celite columns $(3 \mathrm{~g}$ celite: $1 \mathrm{~mL}$ ethylene glycol:propanediol mixture (1:1) over $3 \mathrm{~g}$ celite: $1 \mathrm{~mL}$ water). Purified fractions were dried under nitrogen and resuspended in assay buffer. An aliquot of each sample was removed for estimating recovery, and the remaining volume was assayed in duplicate. Assay values were corrected for plasma volume and individual recoveries following chromatography. Samples from individual snakes were analyzed in eight separate assays (four for $\mathrm{P}, \mathrm{T}$, and $\mathrm{B}$, and four for E2). Mean percent recoveries were $88 \%$ for $\mathrm{P}, 89 \%$ for $\mathrm{T}, 80 \%$ for $\mathrm{E} 2$, and $72 \%$ for $\mathrm{B}$. The mean intra-assay coefficients of variation (CVs) were $16 \%$ for $\mathrm{P}, 13 \%$ for $\mathrm{T}, 13 \%$ for $\mathrm{E} 2$, and $12 \%$ for B. The inter-assay CVs were $17 \%$ for P, $24 \%$ for T, $10 \%$ for $\mathrm{E} 2$, and $16 \%$ for $\mathrm{B}$.

Plasma $\mathrm{T}$ and $\mathrm{B}$ levels were determined in samples from male $C$. atrox using the same methods, except that an ether ethanol hexane extraction was used to purify samples instead of column chromatography. Prior to using this method, we demonstrated parallelism between standard curves and serial dilutions of pooled plasma samples for T and B. Following extraction in $3 \mathrm{~mL}$ ethyl ether, the ether fractions were removed and dried with nitrogen gas, and the samples were resuspended in $1 \mathrm{~mL}$ $90 \%$ ethanol and refrigerated overnight. Samples were then extracted with $2 \mathrm{~mL}$ hexane, the ethanol fractions were removed and dried with nitrogen gas, and the samples were resuspended in assay buffer. Assay values were corrected for plasma volume and individual recoveries. Samples from individual snakes were analyzed in two separate assays for $\mathrm{T}$ and a single assay for B. Mean percent recoveries were $65 \%$ for $\mathrm{T}$ and $66 \%$ for $\mathrm{B}$ (these were lower than female percent recoveries due to the dual extraction). The intra-assay CVs were $13 \%$ for $\mathrm{T}$ and $13 \%$ for $\mathrm{B}$. The inter-assay CV was $3 \%$ for $\mathrm{T}$.

\subsection{Data analysis: females}

In order to distinguish seasonal hormone profiles of females in years that they reproduced from those when they did not, we designated each female snake as either reproductive or non-reproductive for a twelve-month period. If a snake reproduced, it was designated as reproductive for the month of parturition (usually
August) and each of the preceding eleven months. If a snake did not reproduce in the summer, it was designated as non-reproductive for that August and each of the preceding eleven months. In months when multiple blood samples were obtained from a single female, we averaged the values from all the samples for that month to obtain one value. Using SAS (SAS Institute, version 8.2 ), we analyzed mean monthly B, E2, P, and T levels using repeated measures analyses of variance (RMANOVA) with reproductive state as the between-subjects factor, time as the within-subjects factor, and hormone level as the dependent variable. The fact that snakes were at times inaccessible led to missing data. Since standard RMANOVA techniques (e.g., the GLM procedure) require complete data, we used the MIXED procedure (Littell et al., 1996). PROC MIXED inferences for B, E2, and $\mathrm{P}$ were made using the compound symmetry covariance structure, and inferences for $\mathrm{T}$ were made using the autoregressive covariance structure, because these structures minimized Akaike's Information and Schwarz' Bayesian Criteria (Littell et al., 1996). Post hoc comparisons of hormone levels between reproductive and non-reproductive snakes at each month were made with $t$ tests adjusted for an experimentwise Type 1 error rate of 0.05 . The adjusted alpha for controlling Type 1 experimentwise error is $0.05 / n$, where $n=$ the number of time periods $(.05 / 7=0.007)$. Sample sizes of reproductive and non-reproductive snakes at each month are shown in Table 1; post hoc comparisons in the months of March and September must be interpreted with caution because there is only a single sample from reproductive snakes in these months.

\subsection{Data analysis: males}

There was no relationship between plasma $\mathrm{T}$ level and SVL $\left(F_{1,82}=0.111, p=0.74, R^{2}=0.001\right)$ or mass $\left(F_{1,91}=3.106, p=0.08, R^{2}=0.033\right)$. There was also no relationship between plasma B level and SVL $\left(F_{1,82}=\right.$ $\left.1.046, p=0.31, R^{2}=0.013\right) \quad$ or $\quad$ mass $\quad\left(F_{1,91}=0.494\right.$, $\left.p=0.48, R^{2}=0.005\right)$. We ln-transformed $\mathrm{B}$ data and square root-transformed $\mathrm{T}$ data to meet the assumptions of normality and homogeneity of variances; however, all data in figures are shown back-transformed to original values. The fact that we re-captured and therefore resampled some of the males can lead to pseudoreplication if samples from these males are treated as independent samples. Therefore, we randomly selected one sample from each male $(n=103)$ and used these values for analyses (the results were similar when all samples were included). We analyzed mean monthly transformed B and $\mathrm{T}$ levels using the GLM procedure to perform analyses of variance (ANOVA) with month as the factor and $\mathrm{B}$ or $\mathrm{T}$ level as the dependent variable, followed by Tukey's HSD tests to determine in which months the snakes had different hormone levels. Finally, we 
Table 1

Mean monthly steroid hormone levels ( $\mathrm{ng} / \mathrm{ml} \pm 1 \mathrm{SEM}$ ) of female (reproductive and non reproductive) and male Crotalus atrox

\begin{tabular}{|c|c|c|c|c|c|c|}
\hline Month & Sex/condition & $N$ & $17 \beta$ estradiol & Progesterone & Corticosterone & Testosterone \\
\hline \multirow[t]{3}{*}{ March } & Reproductive female & 1 & 3.04 & 0.29 & 10.98 & 2.62 \\
\hline & Non reproductive female & 11 & $0.15 \pm 0.02$ & $0.14 \pm 0.02$ & $41.81 \pm 3.82$ & $0.18 \pm 0.02$ \\
\hline & Male & 9 & - & - & $35.86 \pm 1.67$ & $34.68 \pm 2.70$ \\
\hline \multirow[t]{3}{*}{ April } & Reproductive female & 4 & $26.00 \pm 5.00$ & $1.17 \pm 0.43$ & $58.91 \pm 11.20$ & $4.14 \pm 1.54$ \\
\hline & Non reproductive female & 14 & $0.16 \pm 0.02$ & $0.69 \pm 0.12$ & $32.96 \pm 1.37$ & $0.73 \pm 0.09$ \\
\hline & Male & 23 & - & - & $36.90 \pm 1.09$ & $14.10 \pm 1.10$ \\
\hline \multirow[t]{3}{*}{ May } & Reproductive female & 4 & $32.25 \pm 1.00$ & $3.63 \pm 0.73$ & $17.80 \pm 4.35$ & $13.94 \pm 3.37$ \\
\hline & Non reproductive female & 11 & $1.98 \pm 0.58$ & $0.35 \pm 0.05$ & $32.03 \pm 4.18$ & $0.82 \pm 0.21$ \\
\hline & Male & 10 & - & - & $24.82 \pm 2.49$ & $1.92 \pm 0.26$ \\
\hline \multirow[t]{3}{*}{ June } & Reproductive female & 6 & $2.41 \pm 0.17$ & $27.62 \pm 2.28$ & $28.48 \pm 3.33$ & $0.18 \pm 0.03$ \\
\hline & Non reproductive female & 6 & $0.42 \pm 0.11$ & $0.42 \pm 0.14$ & $21.62 \pm 1.30$ & $0.34 \pm 0.09$ \\
\hline & Male & 18 & - & - & $29.27 \pm 2.34$ & $7.80 \pm 1.32$ \\
\hline \multirow[t]{3}{*}{ July } & Reproductive female & 15 & $0.93 \pm 0.07$ & $17.85 \pm 1.14$ & $82.32 \pm 4.61$ & $0.38 \pm 0.02$ \\
\hline & Non reproductive female & 14 & $0.98 \pm 0.18$ & $0.32 \pm 0.03$ & $26.10 \pm 2.35$ & $0.78 \pm 0.08$ \\
\hline & Male & 25 & - & - & $35.46 \pm 1.98$ & $30.05 \pm 1.45$ \\
\hline \multirow[t]{3}{*}{ August } & Reproductive female & 12 & $0.30 \pm 0.04$ & $9.47 \pm 0.66$ & $127.01 \pm 4.61$ & $0.29 \pm 0.02$ \\
\hline & Non reproductive female & 15 & $0.45 \pm 0.05$ & $0.21 \pm 0.02$ & $14.72 \pm 0.96$ & $0.67 \pm 0.05$ \\
\hline & Male & 24 & - & - & $19.13 \pm 0.59$ & $59.40 \pm 1.64$ \\
\hline \multirow[t]{3}{*}{ September } & Reproductive female & 1 & 0.21 & 0.74 & 39.63 & 0.28 \\
\hline & Non reproductive female & 11 & $0.13 \pm 0.01$ & $0.60 \pm 0.08$ & $65.38 \pm 5.38$ & $0.23 \pm 0.03$ \\
\hline & Male & 46 & - & - & $31.12 \pm 0.95$ & $38.65 \pm 1.18$ \\
\hline \multirow[t]{3}{*}{ October } & Reproductive female & 0 & - & - & - & - \\
\hline & Non reproductive female & 0 & - & - & - & - \\
\hline & Male & 12 & - & - & $33.19 \pm 2.19$ & $36.97 \pm 4.76$ \\
\hline
\end{tabular}

Cells where hormone levels were not measured are designated with " ".

performed a linear regression analysis using untransformed hormone levels to determine whether $\mathrm{T}$ and $\mathrm{B}$ levels were correlated.

\section{Results}

\subsection{Female reproductive cycle}

Using ultrasonography, we found that reproductive female $C$. atrox at our field site showed the first visible evidence of vitellogenesis in April (follicles echogenic and $>10 \mathrm{~mm}$ ). By May, reproductive snakes showed highly enlarged, yolked follicles, which they then ovulated in June, as evidenced by the posterior movement and linear alignment of ova. In July, fetuses were visible as yolk steadily became depleted. In August, there was very little yolk present, and fetal heartbeats were often visible. Parturition in a given year predominantly occurred over a short period (three weeks) in August.

\subsection{Female hormone levels}

The mean monthly steroid levels $(\mathrm{ng} / \mathrm{ml} \pm 1 \mathrm{SEM})$ for reproductive and non-reproductive female $C$. atrox are shown in Table 1.

\subsubsection{7 $\beta$-Estradiol}

The RMANOVA on E2 levels revealed significant effects of reproductive state $\left(F_{1,24}=221.87, p<0.0001\right)$, time $\left(F_{6,74}=93.32, p<0.0001\right)$, and a time by treatment interaction $\left(F_{6,74}=87.59, p<0.0001\right)$. These results indicate that E2 levels were different between reproductive and non-reproductive snakes, varied over time, and changed differently over time in the two groups (Fig. 1A). Circulating levels of E2 were non-detectable or low in non-reproductive snakes throughout the year. Levels were also low in reproductive snakes in July through September, periods corresponding to gestation and postparturition. E2 levels peaked in reproductive snakes in the months of April and May, the period in which mating and vitellogenesis occurs. Post hoc tests showed that reproductive snakes had significantly higher E2 levels than non-reproductive snakes in March, April, May, and June.

\subsubsection{Progesterone}

The RMANOVA on P levels revealed significant effects of reproductive state $\left(F_{1,24}=11.46, p=0.002\right)$, time $\left(F_{6,74}=5.26, p=0.0001\right)$, and a time by treatment interaction $\left(F_{6,74}=5.40, p=0.0001\right)$. These results indicate that $\mathrm{P}$ levels were different between reproductive and non-reproductive snakes, varied over time, and changed differently over time in the two groups (Fig. 1B). Circulating levels of $\mathrm{P}$ were low in non-reproductive snakes throughout the year. Levels were also low in reproductive snakes during March, April, and September, but were significantly higher than those of nonreproductive snakes from May to August. Levels peaked in June, after ovulation occurred, and remained elevated throughout gestation until parturition. 

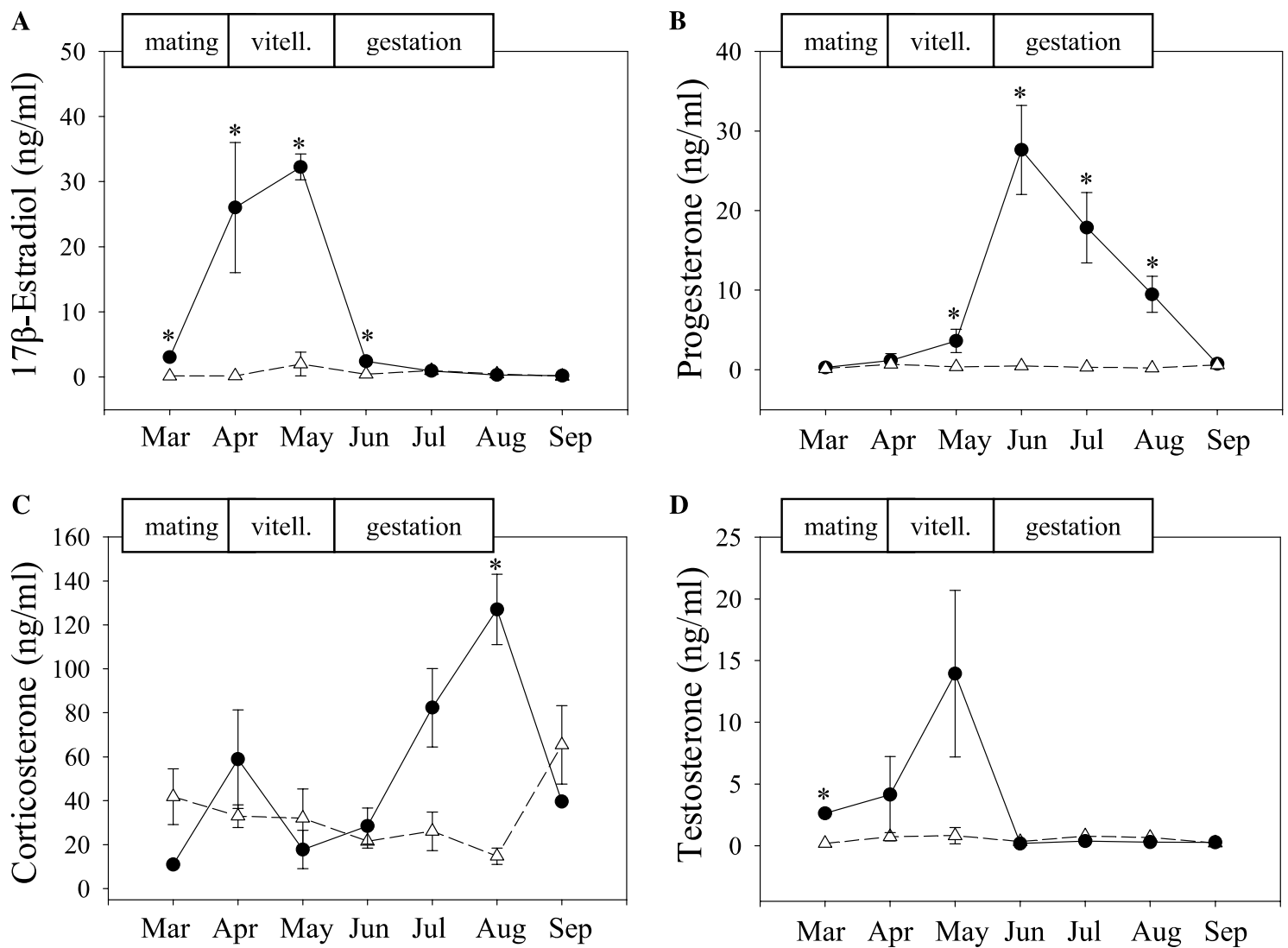

Fig. 1. Monthly plasma levels of (A) $17 \beta$ estradiol, (B) progesterone, (C) corticosterone, and (D) testosterone in reproductive (black circles, solid lines) and non reproductive (white triangles, dashed lines) female Crotalus atrox. Hormone levels in non reproductive snakes were relatively low throughout the year, but were high in reproductive snakes at certain times in the reproductive cycle (significant differences are marked with *, see text for details). Values are presented as means \pm 1 SEM. Approximate timing of spring mating, vitellogenesis ( vitell.), and gestation are indicated in the bars above the graphs.

\subsubsection{Corticosterone}

The RMANOVA on B levels revealed no effect of reproductive state $\left(F_{1,24}=0.76, p=0.39\right)$, a significant time effect $\left(F_{6,74}=3.17, p=0.008\right)$, and a significant time by treatment interaction $\left(F_{6,74}=5.57, p<0.0001\right)$. These results indicate that $B$ levels varied over time and changed differently over time in the two groups (Fig. 1C). Circulating levels of B were relatively constant in non-reproductive snakes throughout the year. In reproductive snakes, B levels rose in July and were significantly higher than those of non-reproductive snakes immediately prior to parturition in August. Reproductive snakes also showed a smaller elevation of B in April (Fig. 1C); however, the difference is not significant due to high variability in B levels among reproductive snakes in this month.

\subsubsection{Testosterone}

The RMANOVA on $\mathrm{T}$ levels revealed significant effects of reproductive state $\left(F_{1,24}=15.02, p=0.0007\right)$, time $\left(F_{6,75}=12.03, p<0.0001\right)$, and a time by treatment interaction $\left(F_{6,73}=11.53, p<0.0001\right)$. These results indicate that $\mathrm{T}$ levels were different between reproductive and non-reproductive snakes, varied over time, and changed differently over time in the two groups (Fig. 1D). Circulating levels of $\mathrm{T}$ were non-detectable or low in non-reproductive snakes throughout the year. Levels were also low in reproductive snakes except in April and May, the time period coinciding with vitellogenesis; however, there was no significant difference in $\mathrm{T}$ levels between reproductive and non-reproductive snakes in these months due to substantial variability in $\mathrm{T}$ levels among reproductive snakes. Reproductive snakes had significantly higher $\mathrm{T}$ levels than non-reproductive snakes in March, but this may be an artifact of the small sample size of reproductive snakes in March.

\subsection{Male hormone levels}

\subsubsection{Testosterone}

Testosterone levels varied significantly among months $(n=103, F=7.34, \mathrm{df}=7, p<0.0001) . \quad$ Testosterone levels are high in early spring, drop during late spring and early summer, and peak in late summer (Fig. 2A). Tukey post hoc tests reveal that $\mathrm{T}$ levels are highest in 

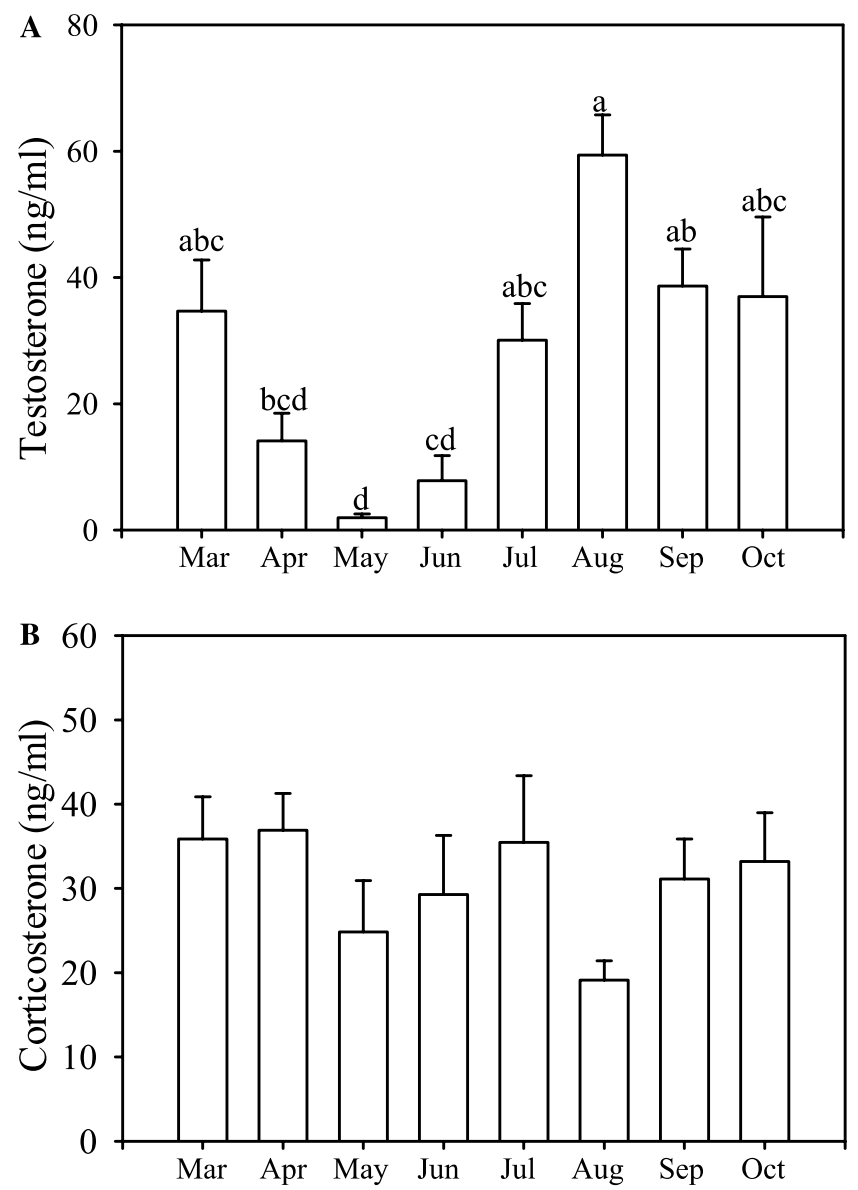

Fig. 2. Monthly mean plasma levels of (A) testosterone and (B) cor ticosterone in male Crotalus atrox. Testosterone levels are high in early spring and late summer, and are low in late spring. Corticosterone levels are uniform throughout the year. Months with significantly different mean hormone levels are designated with different letters. Values are presented as means \pm 1 SEM. Sample sizes are listed in Table 1.

August and lowest in May, with intermediate levels at all other months. The spring and late summer peaks in $\mathrm{T}$ correspond temporally to the two breeding seasons observed in C. atrox at our field site.

\subsubsection{Corticosterone}

Corticosterone levels did not vary among months ( $n=103, F=1.61, \mathrm{df}=7, p=0.14$; Fig. 2B). There was no relationship between $\mathrm{T}$ and $\mathrm{B}$ levels in male $C$. atrox $\left(n=103, F=1.236, p=0.27, R^{2}=0.01\right)$.

\section{Discussion}

The reproductive cycle of $C$. atrox at our field site resembles those reported from other areas inhabited by this wide-ranging species (Aldridge and Duvall, 2002). Snakes were observed mating during two periods: the end of the monsoon season (late August to early Octo- ber) and upon emergence from overwintering (March to April). Females mating in the late summer may store sperm through the winter until ovulation the following June (Schuett, 1992), and may also mate again in the spring. Females at this site do not initiate vitellogenesis in the fall as observed in many species of rattlesnakes, including C. atrox in parts of its range (Aldridge and Duvall, 2002; Rosen and Goldberg, 2002). Instead, females show no evidence of vitellogenesis in March, initiate vitellogenesis in April and May, ovulate in June, and give birth from late July through early September. No female reproduced in both years of this two-year study. Less-than-annual reproduction is commonly observed in rattlesnakes (Klauber, 1972), including C. atrox (Rosen and Goldberg, 2002), although some populations show annual reproduction (Fitch and Pisani, 1993). Frequency of reproduction in many snakes is strongly affected by the rate of energy accumulation (Aubret et al., 2002; Bonnet et al., 1994), and thus environmental differences (i.e., prey availability) rather than physiological differences may explain the intraspecific and interspecific variation in reproductive frequency.

Seasonal steroid hormone profiles of female $C$. atrox resemble those of other reptiles. Levels of the three sex steroids examined (E2, P, and T) were low and did not vary seasonally in non-reproductive snakes, whereas they peaked during vitellogenesis and the spring mating period $(\mathrm{E} 2, \mathrm{~T})$ or gestation $(\mathrm{P})$ in reproductive snakes. In non-reproductive females, B levels were fairly constant throughout the year, whereas reproductive snakes showed peaks during vitellogenesis and at the end of gestation.

Seasonal increases in the sex steroid E2 occur in a variety of reptiles for two main reasons. First, E2 is the primary hormone responsible for stimulating the liver to produce vitellogenins, or egg-yolk proteins (reviewed in Ho et al., 1982), and increases in E2 are correlated with vitellogenic activity in turtles (Ott et al., 2000), alligators (Guillette et al., 1997), lizards (Edwards and Jones, 2001; Radder et al., 2001; Rhen et al., 2000), and snakes (Bonnet et al., 1994; Whittier et al., 1987). Second, increases in E2 commonly occur during the mating season because E2 can stimulate attractivity or receptivity of female reptiles (Rhen and Crews, 2000; Whittier and Tokarz, 1992). In our study, increases in E2 occurred in April and May, supporting a role of E2 in vitellogenesis. However, E2 may not be an important stimulus of attractivity or receptivity since $C$. atrox mate in both spring and fall, yet E2 is elevated only during the spring.

Progesterone levels increase during gestation in a variety of vertebrates for the general purpose of pregnancy maintenance (Custodia-Lora and Callard, 2002). However, the exact role of $\mathrm{P}$, as well as interspecific variation in this role, is not well understood. The pregnancy maintenance properties of $\mathrm{P}$ in viviparous 
vertebrates include inhibition of follicular growth and oviductal contractility (Guillette et al., 1981) as well as maintenance of oviductal vascularity (Mead et al., 1981). Our results mimic those of a previous study (Bonnet et al., 2001) where P peaks early in gestation with a slow decline until parturition, suggesting that parturition may be stimulated by a drop in P levels. Supporting such a role for P, Guillette et al. (1991) showed that administration of exogenous $\mathrm{P}$ delayed parturition in a viviparous lizard. However, similar experimental administration of $\mathrm{P}$ to pregnant aspic vipers did not delay parturition (Bonnet et al., 2001).

An alternate hormonal stimulus of parturition in $C$. atrox might be B. While B is typically considered a "stress hormone" (Greenberg and Wingfield, 1987), its production by the adrenal cortex can occur in response to many factors including reproduction (Romero, 2002). Increases in circulating $\mathrm{B}$ during the mating period and vitellogenesis have been noted in many reptile species (reviewed in Moore and Jessop, 2003; Romero, 2002), and this increase in B may involve its role in energy mobilization for vitellogenesis (Grassman and Crews, 1990; Wilson and Wingfield, 1992). However, other squamate species show peaks in B during the later stages of gestation (DauphinVillemant et al., 1990; Guillette et al., 1997). In mammals, plasma B is elevated during the late stages of gestation because glucocorticoids are key components of the physiological changes leading to parturition (Gibb and Challis, 2002). In reproductive female $C$. atrox, B may have a combined role in mobilizing energy for vitellogenesis and in preparing for parturition, as B levels increase slightly during the spring mating/vitellogenic period and peak at the end of gestation.

Since we brought snakes from the field to the laboratory several weeks prior to parturition, it is possible that the peak in B during the late stages of gestation reflects adrenal activity in response to capture stress rather than reproductive events (Greenberg and Wingfield, 1987). However, this is unlikely because the increase in B occurred immediately prior to parturition despite the fact that snakes were brought into the lab at varying time periods before parturition. Snakes kept in the lab one month before parturition did not show an increase in B earlier than snakes caught one week before parturition (Fig. 3). The B levels of reproductive snakes when they first arrived in the lab were similar to those of the non-reproductive snakes that were still in the field. Corticosterone levels rose within a week before parturition in most snakes, even though snakes were brought to the laboratory a variable number of days before parturition. Furthermore, B levels plummeted at parturition (Fig. 3), whereas if they had increased due to capture stress, they likely would have remained elevated. This suggests that the peak in corticosterone is physiologically related to parturition rather than capture stress.

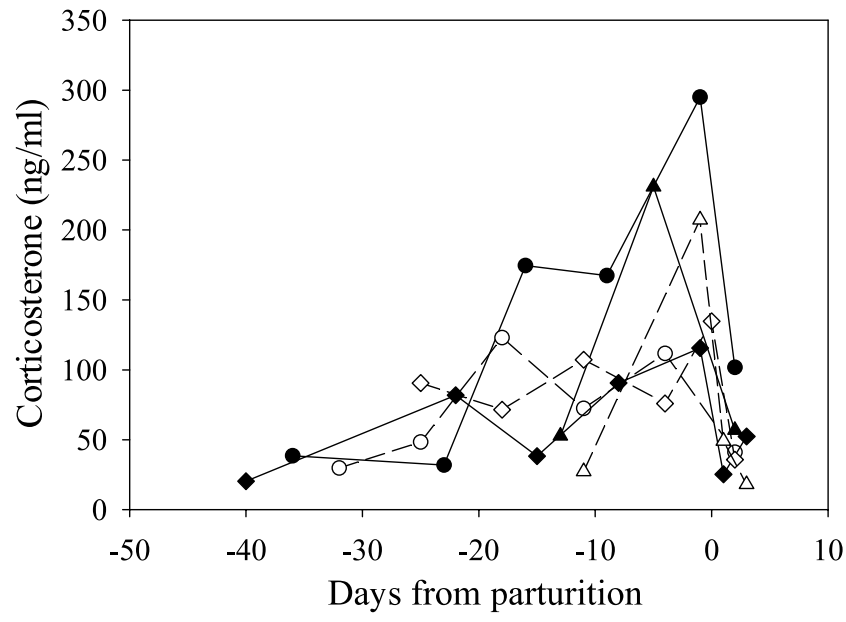

Fig. 3. Change in corticosterone levels in six reproductive female Crotalus atrox prior to parturition. The first sample point for each female represents corticosterone levels in the field at the time of cap ture; all subsequent points are from samples taken in the laboratory. Levels of corticosterone are shown from six representative snakes in order to simplify the graph, but all snakes showed similar corticoste rone profiles around the time of parturition.

We observed a modest increase in $\mathrm{T}$ during May, when reproductive snakes were undergoing vitellogenesis. This increase in $\mathrm{T}$ during vitellogenesis may simply occur because $\mathrm{T}$ is a precursor to $\mathrm{E} 2$ in the biosynthetic pathway (Staub and De Beer, 1997). Alternatively, T may interact with E2 in regulating synthesis of vitellogenins (reviewed in Callard et al., 1990). The function of $\mathrm{T}$ in female reptiles is poorly understood (Staub and De Beer, 1997). An increase in $T$ is evident in females of many taxa during the mating/vitellogenic period (turtles: Hamann et al., 2002; Ott et al., 2000; alligators: Guillette et al., 1997; tuatara: Cree et al., 1992; lizards: Edwards and Jones, 2001; Rhen et al., 2000; and snakes: Saint-Girons et al., 1993; Whittier et al., 1987), but the function of this increase is unknown.

We found that $\mathrm{T}$ levels in male $C$. atrox were elevated during the two breeding seasons (late summer and spring), a trend also observed in two other species of viper with the same mating seasons (Agkistrodon contortix, Schuett, 1997; Crotalus scutulatus, Schuett et al., 2002). Elevation of $\mathrm{T}$ during the mating season is commonly observed in vertebrate taxa, since $\mathrm{T}$ promotes male mating behaviors such as mate-searching and courtship (Agmo and Sodersten, 1975; Balthazart et al., 1985; Lindzey and Crews, 1986). Testosterone levels were lowest in $C$. atrox during May, a time when no mating activity is observed. Testosterone levels may be elevated in the late summer because male rattlesnakes undergo sperm formation at this time (Schuett, 1992). During sperm formation, the renal sex segment, which supplies the sperm with nutrients, become hypertrophied under androgenic control (Prasad and Sanyal, 1969). Males store sperm produced in the late summer 
for use during the following spring mating period (Schuett, 1992). Thus, the elevation in $\mathrm{T}$ in C. atrox coincides with their two mating periods in the spring and late summer, as well as with the physiological process of sperm formation in the late summer.

Many species show correlations between $\mathrm{T}$ and $\mathrm{B}$ levels (Moore and Jessop, 2003). Negative relationships between $\mathrm{T}$ and $\mathrm{B}$ are present in many species because B can suppress sex steroid levels (Greenberg and Wingfield, 1987). However, positive correlations between $\mathrm{T}$ and $\mathrm{B}$ occur in species that experience high energetic demands during the breeding season, where high $\mathrm{T}$ levels promote reproductive behaviors and high $\mathrm{B}$ levels promote energy mobilization (Moore and Jessop, 2003). We found that there was no seasonal variation in B levels in male $C$. atrox during the active season, and $\mathrm{B}$ levels were not related to $\mathrm{T}$ levels. This suggests that $\mathrm{B}$ does not have a strong negative effect on $\mathrm{T}$ levels, a pattern also seen in male garter snakes (Moore et al., 2000). The lack of a positive correlation between $\mathrm{B}$ and $\mathrm{T}$ levels suggests that energetic requirements in male C. atrox may not be substantially increased during the breeding season. However, male rattlesnakes exhibit increased activity during the breeding seasons because they often travel long distances in search of females (Duvall and Schuett, 1997; Klauber, 1972). Low basal metabolic rates and energy requirements of rattlesnakes in comparison to other reptiles of similar size (Beaupre and Duvall, 1998) may allow male $C$. atrox to meet increased energy demands without a concomitant increase in energy mobilization by $\mathrm{B}$; however, this hypothesis remains to be tested experimentally.

In summary, the hormonal profiles of male and female $C$. atrox resemble those of many viviparous vertebrates. In females, maximum elevations occur in E2 during vitellogenesis, $\mathrm{P}$ during gestation, and $\mathrm{B}$ immediately pre-parturition, while in males $\mathrm{T}$ is maximal during the mating seasons. The strong similarities in seasonal levels of steroid hormones across broad taxonomic groups reflect the critical role of these hormones in regulating reproductive events. However, finer-scale interspecific differences may be evidence of plasticity in the reproductive cycle to adapt to ecophysiological pressures. Of particular interest in C. atrox are seasonal differences in the association of hormone profiles with reproductive events. Crews (1984) and Crews et al. (1984) categorize reproduction in vertebrates as either "associated" (mating behavior coincides with gonadal activity) or "dissociated" (mating behavior does not coincide with gonadal activity). In $C$. atrox, females show an E2 peak during the mating/vitellogenesis period in the spring, but have no increase in E2 during the fall mating season, indicating that $\mathrm{E} 2$ is probably associated with vitellogenesis and not with mating in $C$. atrox. Males exhibit increased $\mathrm{T}$ twice in a single annual cycle, once during simultaneous spermatogenesis and mating behavior (fall) and once during mating behavior alone (spring). These results indicate that the reproductive cycle of $C$. atrox, like that of another species of rattlesnake (C. scutulatus; Schuett et al., 2002), cannot be categorized as either "dissociated" or "associated." The temporal differences in the timing of physiological and behavioral events suggest considerable complexity among hormonal, gonadal, and behavioral cycles of $C$. atrox, and suggest that the reproductive cycle is regulated not only by direct hormonal actions, but also by complex hormonal interactions with other hormones or environmental cues. Experimental manipulation of hormone levels and environmental conditions would be a powerful adjunct in elucidating the regulatory mechanisms of the reproductive cycle and the functional significance of differences in seasonal hormone levels among species.

\section{Acknowledgments}

Numerous people helped collect snakes in the field, including X. Bonnet, T. Brennan, M. Feldner, S. Hussein, O. Lourdais, M. Malawy, J. Miller, and J. Slone. We thank M. Moore and M. Orchinik for use of their laboratory facilities for radioimmunoassay procedures. S. Beaupre provided valuable advice regarding statistical analysis. Critical comments from members of the DeNardo laboratory as well as two anonymous reviewers improved the manuscript. Funding was provided by the Arizona State University Department of Biology, the Arizona State University Graduate and Professional Student Association, and the National Science Foundation.

\section{References}

Agmo, A., Sodersten, P., 1975. Sexual behaviour in castrated rabbits treated with testosterone, oestradiol, dihydrotestosterone or oest radiol in combination with dihydrotestosterone. J. Endocrinol. 67, 327332 .

Aldridge, R.D., Duvall, D., 2002. Evolution of the mating season in the pitvipers of North America. Herpetol. Monographs 16, 125.

Aubret, F., Bonnet, X., Shine, R., Lourdais, O., 2002. Fat is sexy for females but not males: the influence of body reserves on reproduction in snakes (Vipera aspis). Horm. Behav. 42, 135147.

Balthazart, J., Schumacher, M., Malacarne, G., 1985. Interaction of androgens and estrogens in the control of sexual behavior in male Japanese quail. Physiol. Behav. 35, 157166.

Beaupre, S.J., Duvall, D., 1998. Variation in oxygen consumption of the western diamondback rattlesnake (Crotalus atrox): implications for sexual size dimorphism. J. Comp. Physiol. B 168, 497506.

Bonnet, X., Naulleau, G., Mauget, R., 1994. The influence of body condition on $17 \beta$ oestradiol levels in relation to vitellogenesis in female Vipera aspis (Reptilia, Viperidae). Gen. Comp. Endocrinol. 93, 424437.

Bonnet, X., Naulleau, G., Bradshaw, D., Shine, R., 2001. Changes in plasma progesterone in relation to vitellogenesis and gestation in 
the viviparous snake Vipera aspis. Gen. Comp. Endocrinol. 121, 8494.

Callard, I.P., Riley, D., Perez, L., 1990. Vertebrate vitellogenesis: molecular model for multihormonal control of gene regulation. Prog. Clin. Biol. Res. 342, 343348.

Crews, D., 1984. Gamete production, sex hormone secretion, and mating behavior uncoupled. Horm. Behav. 18, 2228.

Cree, A., Cockrem, J.F., Guillette Jr., L.J., 1992. Reproductive cycles of male and female tuatara (Sphenodon punctatus) on Stephens Island New Zealand. J. Zool. 226, 199217.

Crews, D., Camazine, B., Diamond, M., Mason, R., Tokarz, R.R., Garstka, W.R., 1984. Hormonal independence of courtship behavior in the male gartersnake. Horm. Behav. 18, 2941.

Custodia Lora, N., Callard, I.P., 2002. Progesterone and progesterone receptors in reptiles. Gen. Comp. Endocrinol. 127, 17.

Dauphin Villemant, C., Leboulenger, F., Xavier, F., Vaudry, H., 1990. Adrenal activity in the female lizard Lacerta vivipara Jacquin associated with breeding activities. Gen. Comp. Endocrinol. 78, 399413.

Duvall, D., Schuett, G.W., 1997. Straight line movement and com petitive mate searching in prairie rattlesnakes, Crotalus viridis viridis. Anim. Behav. 54, 329334.

Edwards, A., Jones, S.M., 2001. Changes in plasma progesterone, estrogen, and testosterone concentrations throughout the repro ductive cycle in female viviparous Blue Tongued Skinks, Tiliqua nigrolutea (Scincidae), in Tasmania. Gen. Comp. Endocrinol. 122, 260269.

Fitch, H.S., Pisani, G.R., 1993. Life history traits of the Western Diamondback Rattlesnake (Crotalus atrox) studied from roundup samples in Oklahoma. Occ. Pap. Kans. Mus. Nat. Hist. 156, 124.

Gans, C., Crews, D. (Eds.), 1992. Biology of the Reptilia, vol. 18, Physiology E: Hormones, Brains, and Behavior. Univ. of Chicago Press, Chicago.

Gibb, W., Challis, J.R., 2002. Mechanisms of term and preterm birth. Obstet. Gynaecol. Can. 24, 874883.

Grassman, M., Crews, D., 1990. Ovarian and adrenal function in the parthenogenic whiptail lizard Cnemidophorus uniparens in the field and laboratory. Gen. Comp. Endocrinol. 76, 444450.

Greenberg, N., Wingfield, J.C., 1987. Stress and reproduction: reciprocal relationships. In: Norris, D.O., Jones, R.E. (Eds.), Hormones and Reproduction in Fishes, Amphibians and Reptiles. Plenum, New York, pp. 461503.

Guillette Jr., L.J., Spielvogel, S., Moore, F.L., 1981. Luteal develop ment, placentation, and plasma progesterone concentration in the viviparous lizard Sceloporus jarrovi. Gen. Comp. Endocrinol. 43, 2029.

Guillette Jr., L.J., Demarco, V., Palmer, B., 1991. Exogenous progesterone or indo methacin delays parturition in the viviparous lizard Sceloporus jarrovi. Gen. Comp. Endocrinol. 81, 105112.

Guillette Jr., L.J., Woodward, A.R., Crain, D.A., Masson, G.R., Palmer, B.D., Cox, M.C., You Xiang, Q., Orlando, E.F., 1997. The reproductive cycle of the female American Alligator (Alligator mississippiensis). Gen. Comp. Endocrinol. 108, 87101.

Hamann, M., Jessop, T.S., Limpus, C.J., Whittier, J.M., 2002. Interactions among endocrinology, seasonal reproductive cycles and the nesting biology of the female green sea turtle. Marine Biol. 140, 823830 .

Ho, S.M., Kleis, S., McPherson, R., Heisermann, J., Callard, I.P., 1982. Regulation of vitellogenesis in reptiles. Herpetologica 38,40 50.

Klauber, L.M., 1972. Rattlesnakes: Their Habits, Life Histories, and Influence on Mankind. University of California Press, Berkeley, CA.

Lindzey, J., Crews, D., 1986. Hormonal control of courtship and copulatory behavior in male Cnemidophorus inornatus, a direct sexual ancestor of a unisexual, parthenogenetic lizard. Gen. Comp. Endocrinol. 64, 411418.
Littell, R.C., Milliken, G.A., Stroup, W.W., Wolfinger, R.D., 1996. SAS System for Mixed Models. SAS Institute, Cary, NC.

Mead, R.A., Eroschenko, V.P., Highfill, D.R., 1981. Effects of progesterone and estrogen on the histology of the oviduct of the garter snake, Thamnophis elegans. Gen. Comp. Endocrinol. 45, 345354.

Moore, I.T., Jessop, T.S., 2003. Stress, reproduction, and adrenocor tical modulation in amphibians and reptiles. Horm. Behav. 43, 39 47.

Moore, M.C., Lindzey, J., 1992. The physiological basis for sexual behavior in male reptiles. In: Gans, C., Crews, D. (Eds.), Biology of the Reptilia, vol. 18. University of Chicago Press, Chicago, pp. 70 113.

Moore, I.T., Lerner, J.P., Lerner, D.T., Mason, R.T., 2000. Relation ships between annual cycles of testosterone, corticosterone, and body condition in male Red spotted Garter Snakes, Thamnophis sirtalis concinnus. Physiol. Biochem. Zool. 73, 307312.

Moore, M.C., Thompson, C.W., Marler, C.A., 1991. Reciprocal changes in corticosterone and testosterone levels following acute and chronic handling stress in tree lizards, Urosaurus ornatus. Gen. Comp. Endocrinol. 81, 217226.

Norris, D.O., 1997. Vertebrate Endocrinology. Academic Press, San Diego, CA.

Ott, J.A., Mendonça, M.T., Guyer, C., Michener, W.K., 2000. Seasonal changes in sex and adrenal steroid hormones of gopher tortoises (Gopherus polyphemus). Gen. Comp. Endocrinol. 117, 299312.

Prasad, M.R.N., Sanyal, M.K., 1969. Effect of sex hormones on the sexual segment of kidney and other accessory reproductive organs of the Indian House Lizard Hemidactylus flaviviridis Ruppell. Gen. Comp. Endocrinol. 12, 110118.

Radder, R.S., Shanbhag, B.A., Saidapur, S.K., 2001. Pattern of sex steroid hormone levels during reproductive cycles of male and female tropical lizard, Calotes versicolor. Gen. Comp. Endocrinol. 124, 285292.

Rhen, T., Crews, D., 2000. Organization and activation of sexual and agonistic behavior in the leopard gecko, Eublepharis macularius. Neuroendocrinol. 71, 252261.

Rhen, T., Sakata, J.T., Zeller, M., Crews, D., 2000. Sex steroid levels across the reproductive cycle of female leopard geckos, Eublepharis macularius, from different incubation temperatures. Gen. Comp. Endocrinol. 118, 322331.

Romero, L.M., 2002. Seasonal changes in plasma glucocorticoid concentrations in free living vertebrates. Gen. Comp. Endocrinol. 128, 124 .

Rosen, P.C., Goldberg, S.R., 2002. Female reproduction, from Arizona in the western diamond backed rattlesnake, Crotalus atrox (Serpentes: Viperidae). Tex. J. Sci. 54, 347356.

Saint Girons, H., Bradshaw, S.D., Bradshaw, F.J., 1993. Sexual activity and plasma levels of sex steroids in the aspic viper Vipera aspis L. (Reptilia, Viperidae). Gen. Comp. Endocrinol. 91, 287 297.

Schuett, G.W., 1992. Is long term sperm storage an important component of the reproductive biology of temperate pitvipers. In: Campbell, J.A., Brodie Jr., E.D. (Eds.), Biology of the Pitvipers. Selva, Tyler, Texas, pp. 169184.

Schuett, G.W., 1997. Annual cycle of testosterone in male copper heads, Agkistrodon contortix (Serpentes: Viperidae): relationship to timing of spermatogenesis, mating, and agonistic behavior. Gen. Comp. Endocrinol. 105, 417424.

Schuett, G.W., Carlisle, S.L., Holycross, A.T., O'Leile, J.K., Hardy Sr., D.L., Van Kirk, E.A., Murdoch, W.J., 2002. Mating system of male Mojave Rattlesnakes (Crotalus scutulatus): seasonal timing of mating, agonistic behavior, spermatogenesis, sexual segment of the kidney, and plasma sex steroids. In: Schuett, G.W., Hoggren, M., Douglas, M.E., Greene, H.W. (Eds.), Biology of the Vipers. Eagle Mountain Publishing, Eagle Mountain, Utah, pp. 515532. 
Staub, N.L., De Beer, M., 1997. The role of androgens in female vertebrates. Gen. Comp. Endocrinol. 108, 124.

Taylor, E.N., Schuett, G.W., 2004. Effects of storage time and temperature on the stability of steroid hormones in blood samples from a squamate reptile. Herpetol. Rev. 35, 14 17.

Whittier, J.M., Mason, R.T., Crews, D., 1987. Plasma steroid hormone levels of female red sided garter snakes, Thamnophis sirtalis parietalis, relationship to mating and gestation. Gen. Comp. Endocrinol. 67, 3343
Whittier, J.M., Tokarz, R.R., 1992. Physiological regulation of sexual behavior in female reptiles. In: Gans, C., Crews, D. (Eds.), Biology of the Reptilia, vol. 18, Hormones, Brain, and Behavior, University of Chicago Press, Chicago, Illinois, pp. 2469.

Wilson, B.S., Wingfield, J.C., 1992. Correlation between female reproductive condition and plasma corticosterone in the lizard Uta stansburiana. Copeia 92, 691697.

Wingfield, J.C., Jacobs, J., Hillgarth, N., 1997. Ecological constraints and the evolution of hormone behavior interrelationships. Ann. N. Y. Acad. Sci. 807, 2241. 